\title{
O cotidiano das enfermeiras na oncologia pediátrica
}

\author{
The daily life of nurses in pediatric oncology \\ El cotidiano de las enfermeras en oncología pediátrica
}

Recebido: 21/01/2021 | Revisado: 31/01/2021 | Aceito: 03/02/2021 | Publicado: 10/02/2021

Patrícia Quintans Cundines Pacheco

ORCID: https://orcid.org/0000-0002-2256-3491

Hospital Federal dos Servidores do Estado, Brasil

E-mail: patricia_quintans@hotmail.com

Sonia Regina de Souza

ORCID: https://orcid.org/0000-0001-7981-0038 Universidade Federal do Estado do Rio de Janeiro, Brasil E-mail: sonia.souza@unirio.br

Florence Romijn Tocantins

ORCID: https://orcid.org/0000-0002-1968-8701 Universidade Federal do Estado do Rio de Janeiro, Brasil

E-mail: florenceromijn@hotmail.com

Leila Rangel da Silva

ORCID: https://orcid.org/0000-0003-1831-0982 Universidade Federal do Estado do Rio de Janeiro, Brasil E-mail: leila.silva@unirio.br

Izabela da Silva Pinheiro

ORCID: https://orcid.org/0000-0003-1609-7778 Universidade Federal do Estado do Rio de Janeiro, Brasil E-mail: izabelapinheiro@live.com

\begin{abstract}
Resumo
Objetivos: Analisar as dimensões ação e afeto no contato cotidiano das enfermeiras na oncologia pediátrica e discutir as implicações das dimensões ação e afeto na prática das enfermeiras na oncologia pediátrica. Método: Estudo qualitativo a luz do referencial teórico de cotidiano de Agnes Heller. Participaram do estudo 21 enfermeiras selecionadas pela técnica de amostragem Bola de neve. Os dados foram produzidos por entrevista semiestruturada mediada por produção artística baseada na técnica de criatividade e sensibilidade e submetidos à análise temática. Resultados: Nas ações das enfermeiras se interpenetraram a especialidade oncologia e as especificidades da criança. $\mathrm{Na}$ dimensão afeto constatou-se uma inclinação, atitude de proteção da enfermeira para a criança e sua família diante da ruptura de vínculos e da copresença da morte resultando em compaixão. Conclusão: Para as enfermeiras, o contato cotidiano na oncologia pediátrica foi desafiante e as potencialidades se mostraram limitadas devido à demanda emocional gerada pela empatia e pelo envolvimento pessoal na assistência às crianças e suas famílias, gerando desgaste profissional e fadiga por compaixão.
\end{abstract}

Palavras-chave: Enfermagem pediátrica; Enfermagem oncológica; Cuidados de enfermagem.

\begin{abstract}
Objectives: To assess the dimensions of action and affection in daily contact of nurses in pediatric oncology and discuss the implications of the dimensions action and affection in practice of nurses in pediatric oncology. Methods: Qualitative study light of the theoretical framework of Agnes Heller everyday. Study participants were 21 nurses selected by sampling technique Snowball. The data were produced by semi-structured interview mediated artistic production based on the technique of creativity and sensitivity and submitted to thematic analysis. Result: In the actions of the nurses are interpenetrated oncology specialty and children's particular circumstances. The affection dimension found up a slope, nurse protective attitude to the child and family on the rupture of ties and co-presence of death resulting in compassion. Conclusion: For the nurses daily contact in pediatric oncology was challenging and the potential proved limited due to the demand generated by emotional empathy and the personal involvement in assisting children and their families, creating professional wear and compassion fatigue.
\end{abstract}

Keywords: Pediatric nursing; Oncology nursing; Nursing care.

\section{Resumen}

Objectivos: Analizar las dimensiones de la acción y el afecto en contacto cotidiano de las enfermeras en oncología pediátrica y discutir las implicaciones de la acción dimensiones y afecto en la práctica de las enfermeras en oncología pediátrica. Métodos: Estudio cualitativa la luz del marco teórico de cotidiano del Agnes Heller. Los del estudio fueron 21 enfermeras seleccionados por la bola de nieve técnica de muestreo. Los datos fueron producidos por entrevista 
mediada por la producción artística semiestructurada basada en la técnica de la creatividad y la sensibilidad y sometidos al análisis temático. Resultado: En las acciones de las enfermeras están interpenetrados especialidad de Oncología y las circunstancias particulares de los niños. La dimensión afecto encuentra en una pendiente, actitud protectora enfermera para el niño y la familia en la ruptura de los lazos y los co-presencia de la muerte que resulta en la compasión. Conclusión: Para las enfermeras contacto diario en oncología pediátrica fue un reto y demostró el potencial limitado debido a la demanda generada por la empatía emocional y la implicación personal en la asistencia a los niños y sus familias, la creación de desgaste profesional y fatiga de la compasión.

Palabras clave: Enfermería pediátrica; Enfermería oncológica; Atención de enfermería .

\section{Introdução}

O cotidiano da enfermeira na oncologia pediátrica se constitui em um espaço onde são realizadas atividades comuns a especialidade, reproduzidas em forma de ritual ao longo do tempo, mas que não são necessariamente realizadas de maneira igual, considerando que cada enfermeira, além de ser dotada de conhecimentos e habilidades próprias, também é uma pessoa particular com necessidades e percepções em relação a si e ao outro. O que há de comum é que todas formam e representam um grupo social que interage nas diversas dimensões do contato cotidiano (Pacheco, 2015).

O contato cotidiano é a base e o reflexo das relações sociais que se estabelecem através das ações diretas sobre o outro, dos afetos que orientam o contato, do espaço que se estabelecem as relações cotidianas e do tempo cotidiano (Heller, 1970).

E esse contato cotidiano é por si só heterogêneo (Heller, 1970) e as relações interpessoais no cenário hospitalar se estabelecem entre as crianças, suas famílias e demais profissionais de saúde. O espaço hospitalar e tudo que nele se encontra se constitui e faz parte do cotidiano da enfermagem.

Para entender estas atividades heterogêneas, é necessário apropriar-se das objetivações (Heller, 1970). Quando a enfermeira lança mão de uma linguagem própria do mundo infantil para explicar um cuidado à criança, ela transforma aquela ação a ponto de alcançar a compreensão da criança e isso é objetivação. Da mesma maneira faz com a família da criança remodelando as palavras ou sentimentos de difícil assimilação até a forma que seja compreendida, ou melhor, aceita.

Há que se pensar em todos os objetos e na própria arquitetura do cenário hospitalar sem os quais não haveria sequer condições de se permanecer naquele ambiente, se não se investisse nas objetivações. Enfeita-se o espaço para se minimizar o impacto. Para criança, se o suporte de soro não pudesse servir de carrinho para seus passeios no corredor da enfermaria, seria absolutamente mais difícil aceitá-lo apenas como objeto para pendurar seus medicamentos.

Para compreender a tríade criança com câncer, família e equipe de enfermagem, deve-se considerar a formação da equipe de enfermagem em especial quanto aos aspectos psicológicos visando um envolvimento emocional efetivo e facilitador para o cuidar da criança com câncer (Anjos, Santo, \& Carvalho, 2015).

Nesse sentido, é preciso compreender o contexto vivenciado pelo paciente oncológico pediátrico visando minimizar os impactos negativos que o ambiente hospitalar e o tratamento causam na criança e seus familiares. Portanto, é fundamental o cuidado humanizado de acordo com os fundamentos de enfermagem (Nunes, Canabarro \& Carvalho, 2018).

De tal modo, que as ações são mediadas pelos afetos, os sentimentos de amor que nos liga àquelas pessoas, cujos contatos são importantes no cotidiano. Nesse sentido, os afetos que orientam a vida cotidiana são decisivos nas relações. Quanto mais intensos, quanto mais baseados na igualdade, quanto mais ricos em conteúdo, mas humanizados são e marcam a vida das pessoas. Essas relações são as de mais alto valor da vida cotidiana (Heller, 1970).

Portanto, para realizar este estudo foi necessário se aproximar do cotidiano de quem realiza as ações buscando conhecer o espaço das relações e das práticas no cenário da oncologia pediátrica.

Assim, o interesse desta pesquisa foi motivado por entender as peculiaridades do contato cotidiano na prática assistencial das enfermeiras na oncologia pediátrica, sendo os objetivos: Analisar as dimensões ação e afeto no contato cotidiano das enfermeiras na oncologia pediátrica e discutir as implicações das dimensões ação e afeto no cotidiano das enfermeiras na 
oncologia pediátrica.

\section{Metodologia}

O presente artigo é um recorte de uma pesquisa de mestrado (Pacheco, 2015). Trata-se de um estudo com abordagem qualitativa vinculada ao referencial teórico de contato cotidiano de Agnes Heller (Heller, 1970). Filosofa nascida na cidade de Budapeste, Hungria em 1929, cujo seus conhecimentos se articulam ao objeto desse estudo.

Uma das premissas principais de Heller é que o homem já nasce inserido em sua cotidianidade e seu amadurecimento significa que o indivíduo adquiriu todas as habilidades imprescindíveis para a vida cotidiana da sociedade em questão. Em toda a sociedade há uma vida cotidiana e todo homem independente do seu local ocupado na divisão de trabalho tem uma vida cotidiana (Heller, 2014).

Tendo como eixo norteador o referencial teórico, para a coleta de dados, utilizou-se a Técnica de Amostragem Não Probabilística de Conveniência Associada à Amostragem em Rede ou Bola de Neve. Nesta técnica o pesquisador escolhe os primeiros participantes por meio da sua própria rede de contatos profissionais, sendo estes denominados sementes. As sementes por sua vez indicam os próximos que são chamados de filhas e assim, é formada a cadeia de referência. A cadeia de referência pode crescer tanto quanto for interessante para o pesquisador conhecer o objeto de pesquisa (Vinuto, 2014).

A escolha da amostragem não probabilística se deu por utilizar-se de amostras não randômicas o que permite que o pesquisador qualitativo selecione pessoas com determinado conhecimento e articuladas com a temática (Polit \& Beck, 2011).

Os critérios de inclusão para todas as participantes sejam estas sementes ou filhas foram: profissionais que possuíam seus currículos cadastrados na Plataforma Lattes e que atendiam aos filtros de busca: formação acadêmica (graduação, especialização, mestrado ou doutorado), atuação profissional (ciências da saúde, área enfermagem, subárea enfermagem pediátrica), residentes no estado do Rio de Janeiro e experiência de pelo menos dois anos na oncologia pediátrica em algum momento de sua atividade profissional. Como critérios de exclusão foram eliminados do estudo os profissionais indicados que não responderam por duas tentativas de contato por meio de telefone e endereço eletrônico.

Para esta pesquisa foram convidadas seis enfermeiras sementes com experiência na oncologia pediátrica no estado do Rio de Janeiro que indicaram 15 "filhas". Assim, a amostra total foi composta de 21 enfermeiras.

A coleta de dados se deu por meio de entrevista semiestruturada mediada por produção artística (PA), Técnica de Criatividade e Sensibilidade (TCS): “Almanaque” do Método Criativo-Sensível (MCS) (Cabral, 1998).

A TCS Almanaque consiste na produção de dados por meio de recorte e colagem de figuras em papel, resultando em uma PA. Autores experientes no uso da criatividade e a sensibilidade na produção de dados de pesquisa ressaltam a importância de se apreender o mundo imaginário do sujeito de modo a transcender a racionalidade e a diversidade das experiências e vivências com o emergir da expressão criativa e sensível (de Souza Minayo, Deslandes \& Gomes, 2011).

A produção de dados ocorreu de janeiro a março de 2015 em um encontro individual com cada participante da pesquisa, em sala preparada para este fim, contendo mesa e cadeiras, e livre de influências externas.

Quanto à técnica de entrevista, optou-se pela entrevista projetiva a partir da imagem produzida pela participante. Essa modalidade de entrevista se constitui em um convite ao entrevistado para falar sobre o que vê ou lê e deve ser utilizada, quando se precisa discorrer sobre assuntos difíceis e delicados (de Souza Minayo et al., 2011). Com essa perspectiva e partindo da produção artística das próprias participantes sobre o seu cotidiano, foi realizada a entrevista.

Os encontros correram em local, previamente, marcado à conveniência das participantes. As falas foram gravadas em mídia digital e, posteriormente, transcritas em um formato codificado e literal. O tempo total de falas gravadas foi de 7 horas 10 minutos e 24 segundos. Para a confecção das produções artísticas, o tempo gasto pelas participantes perfez um total de aproximadamente 20 horas de duração. 
Foram utilizados dois critérios para o encerramento do trabalho de campo. O primeiro se deu quando foi observado que por meio dos depoimentos das participantes já foi possível identificar o ponto de saturação (de Souza Minayo et al., 2011) visto que a quantidade de informações fornecidas proporcionou o entendimento das pesquisadoras sobre o sentido do grupo estudado. E o segundo devido ao fato de que todas as enfermeiras que foram indicadas, que atenderam aos critérios de inclusão e ao chamado para a pesquisa compuseram a amostra.

As participantes assinaram o Termo de Consentimento Livre e Esclarecido, em conformidade com a Resolução 466/2012 do Conselho Nacional de Saúde (CNS), que dispõem sobre a pesquisa envolvendo seres humanos (Brasil, 2012). Foram identificadas pela letra $\mathrm{E}$ e pelo número da entrevista quando participante semente. E quando participante filha pela letra $\mathrm{E}$ seguida do respectivo número da semente que a indicou e número por ordem desta indicação. O projeto foi aprovado pelo Comitê de Ética em Pesquisa da Universidade Federal do Estado do Rio de Janeiro (CEP/UNIRIO) no ano de 2014 sob o Parecer ${ }^{\circ}$ 913.315 .

Para a análise dos dados optou-se pela análise temática que se desenvolve em três etapas: Pré-Análise; Exploração do material e Tratamento dos resultados/Inferência/Interpretação cuja finalidade foi identificar os núcleos de sentido que tinham diálogo com objetivos do estudo e pressupostos iniciais e que nortearam as conclusões do pesquisador e a articulação com os conceitos teóricos utilizados (de Souza Minayo et al., 2011).

Por serem mais expressas nas narrativas das participantes, optou-se pela análise das dimensões ação e afeto do contato cotidiano à luz do referencial teórico. Assim, as falas foram agrupadas em seis subunidades, conforme Figuras 1 e 2:

Figura 1 - Dimensão Ação - o outro como objetivo - Rio de Janeiro, RJ, Brasil, 2015.

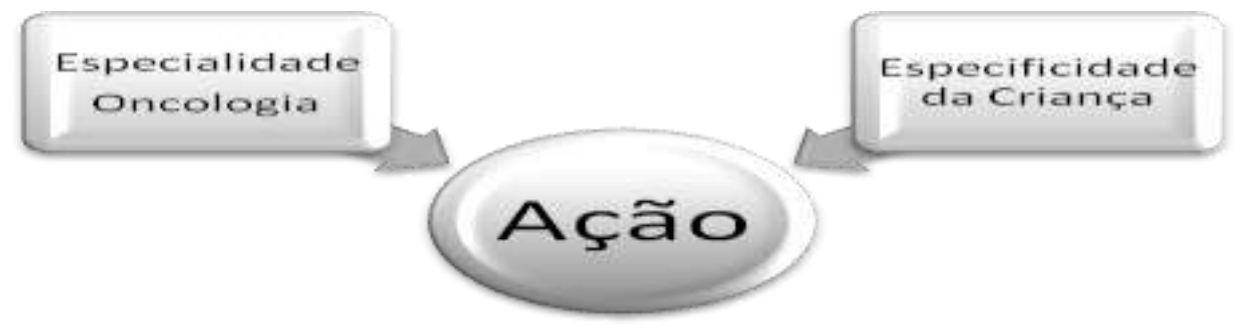

Fonte: Autores.

Figura 2 - Dimensão Afeto - orienta as relações no contato cotidiano - Rio de Janeiro, RJ, Brasil, 2015.

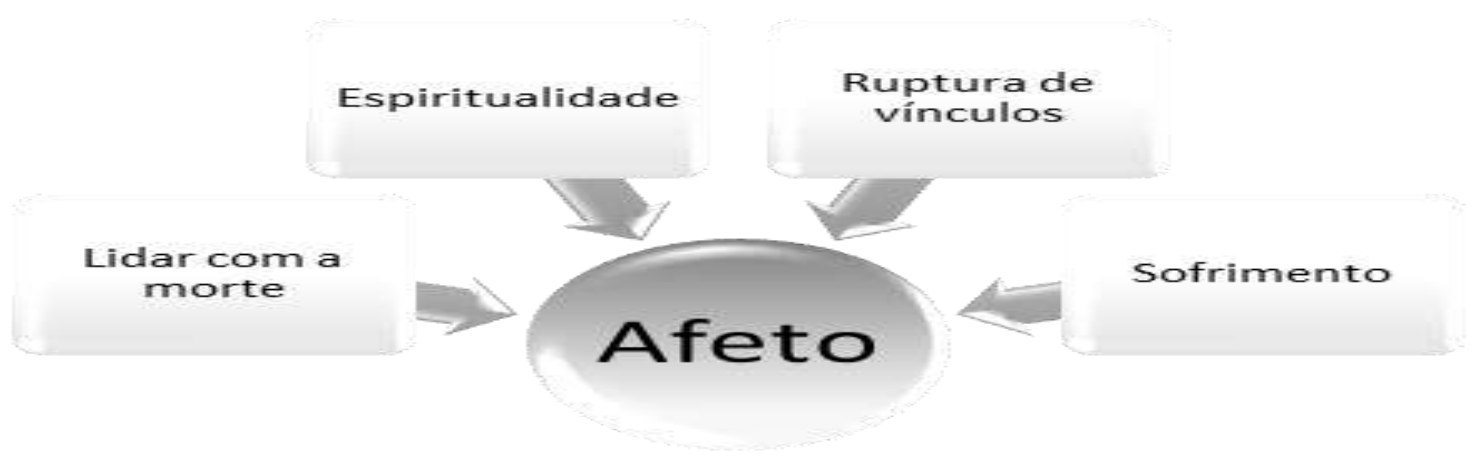

Fonte: Autores.

\section{Resultados}

A análise dos dados evidenciou dois tópicos de análise: A ação da enfermeira na Oncologia Pediátrica - A convergência entre o técnico e o simbólico; O afeto que orienta as relações na Oncologia Pediátrica - A compaixão. 


\section{A ação da enfermeira na Oncologia Pediátrica - A convergência entre o técnico e o simbólico.}

No que se refere ao lidar no contato cotidiano com a doença e seus impactos na criança, a depoente E4 se expressou por meio de estratégias para executar ações de enfermagem assistenciais e gerenciais:

(...) o câncer é uma doença impactante (...) a enfermeira começa (...) com o paciente bonitinho, com cabelinho, sem nenhuma mancha e hematoma, com o peso direitinho e daqui a pouco (...) o teu paciente vai se transformando (...) tentando lidar com vários aspectos: criança chorando, criança falando, criança com desenhos (...) que é como eu me senti e sinto (...) com todas essas questões do paciente oncológico. Muitas vezes, se sentindo a bruxa da situação (...) (E4).

$\mathrm{O}$ cuidado de enfermagem em oncologia pediátrica demanda desgaste físico e emocional por exigir da enfermeira habilidade para dar conta do excesso de atribuições assistenciais e gerenciais, além da capacidade de lidar com o sofrimento das crianças e suas famílias no cotidiano do cuidado.

(...) eu acredito que sejam profissionais que fazem a diferença (...) é uma carga de trabalho muito pesada, assim, para um enfermeiro tanto assistencial quanto gerencial (...) além de lidar com a criança com todo aquele sofrimento que a doença causa você têm inúmeros procedimentos, aquela criança demanda um cuidado muito intenso (...) a gente lida com a família o tempo inteiro, não só a criança e não tem como você desvincular o seu cuidado da criança com o da família (...) (E3.4).

Na mesma abordagem, uma depoente considerou os desafios de assistir a criança, entretanto mencionou estratégias que perpassaram a ação do fazer-técnico relacionando assim, a ação à especificidade da criança com câncer:

(...) o lúdico, o cuidado as crianças. Eu acho que (...) além de toda essa questão técnica, isso vai muito mais do que a gente está falando aqui, eu acho que é a sensibilização dessa equipe, porque existem muitas particularidades, muitas peculiaridades no cuidado a criança oncológica (...) (E6.1).

O modelo assistencial foi apontado por uma depoente, que fez reflexões acerca da necessidade de um planejamento em equipe na oncologia pediátrica, considerando a complexidade do trabalho.

(...) é tratar da doença? É tratar o paciente respeitando como um ser humano ou você quer só tratar somente o câncer?

(...). Se cada um tiver um jeito de pensar diferente é muito complicado, enquanto uns querem tratar o paciente, outros querem tratar a doença e aí você não consegue planejar (...) é a vitória do gerente, quando ele consegue (...) que toda a sua equipe trabalhe com um objetivo comum (...) a vitória é da equipe inteira (...) é você assistir aquela criança e o seu familiar nas suas necessidades básicas. Não só voltado à doença (...) (E1.4).

A depoente E2.1 mencionou as estratégias que utilizou para gerenciar enfermeiras que cuidam de crianças com câncer e a organização da unidade de internação, considerando uma proposta gerencial mais humanizada. Para tanto, ela também destacou a necessidade de repensar os modelos de gestão na especialidade:

(...) eu acho que a gente precisa definir um modelo de gestão que se adapte aos dias de hoje (...) têm dias que a gente é mais terapeuta do que chefe. (...) Você recebe um monte de coisas para carregar (...) você recebe isso como um 
quebra-cabeça desarrumado e que você precisa arrumar! Você tenta equilibrar tudo para depois você entrar na gestão e aí você vai arrumar todo o teu serviço (...) é o que eu tento fazer no meu dia a dia da gestão (...) (E2.1).

No que diz respeito à criança, as depoentes ressaltaram as estratégias para cuidar, mencionando a singularidade da criança como uma necessidade a ser considerada no planejamento da assistência da enfermeira.

(...) cada criança é um mundo a ser explorado (...) exige nossa adaptação para a melhor forma de alcançá-la (...) algumas crianças levam tudo com muita facilidade outras sofrem muito por coisas que a maioria nem sofre tanto assim (...) punção de cateter, punção periférica, têm crianças que levam isso super bem (...) tento buscar estratégias, tentando minimizar o sofrimento da criança e fazer com que a vinda dela para cá fosse menos sofrida (...) (E1).

Conforme o relato abaixo, a enfermeira possibilitou que a criança expressasse seus desejos. Com isso, acolheu e interagiu de forma positiva, tendo como resultado de sua ação, a recompensa por proporcionar alegria e bem-estar à criança em cuidado intensivo.

(...) ele quer uma coisa que é impossível em um hospital (...) como nós já vimos criança que queria empinar uma pipa na UTI e foi possivel realizar um sonho (...) realizar sonhos de crianças que estão em tratamento é uma atividade rotineira na assistência à criança com câncer (...) (E2).

\section{$O$ afeto que orienta as relações na Oncologia Pediátrica - A compaixão}

A depoente narrou conversa com uma integrante da equipe de enfermagem, explicando como the prestou ajuda no enfrentamento em lidar com o outro no espaço das relações:

(...) às vezes, a gente foge! Eu lembro que teve (uma funcionária) uma vez que, eu até me emociono (lágrimas). (...) Ela estava fugindo, e se escondendo da mãe, ai eu falei para ela: "por que você está se escondendo"? Ela me falou que não ia aguentar e eu perguntei: "Você tem medo de que? De chorar, chorar com ela? É isso que ela quer! Se permita chorar com ela! De sofrer com ela"! E eu me permito e falo isso para a equipe, porque eles choram mesmo. (E3.2).

O espaço das relações pode resultar em (des)afetos no contato cotidiano das enfermeiras, entretanto por meio da reconstrução das ações mediadas pelo afeto, as enfermeiras dão sentido ao cuidar.

(...) muitas vezes a gente vê as nossas crianças assim, mutiladas e deformadas, mas para gente da oncologia pediátrica elas são sempre lindas (...) (E5.1).

A participante mencionou o impacto que o diagnóstico do câncer causou em sua vida particular, relacionando o significado que o adoecimento teve para si ao das pessoas que cuida em seu cotidiano:

(...) monstrinho para mim é a representação da oncologia, do câncer, e eu já vivenciei isso (...) é um monstro que fica e está sempre e eternamente (...) mesmo dizendo que eu estou curado e tal, mas aquilo fica, porque é uma coisa que acontece "booom" de repente e vem para querer te destruir mesmo. (...) Quem não gosta de cuidar não deve seguir na enfermagem. Eu acho que enfermagem é cuidar sim, e cuidar do doente, mexer com o doente, tocar no doente, interagir 
com o doente, participar de todas essas partes feias que (...) a gente encontra no doente, mas também tem muita coisa boa também. (E1.5).

O desafio de lidar no espaço das relações onde coexiste a possibilidade da ruptura de vínculos e copresença da morte foi evidenciado no depoimento:

(...) uma criança transplantada (...) está, muitas vezes, na última chance de tratamento que ela tem (...) ocorre à pressão dos pais (...) temos que estar muito bem com essas questões trabalhadas junto à equipe para que se possa entender que ali está vida do meu filho (da criança), da minha filha (...) (E2.3).

Por outro lado, uma depoente mencionou o sofrimento que vivenciou pela ruptura do vínculo de seu papel de enfermeira junto à criança em processo de morte e sua família:

(...) é muito difícil você falar para a família quando a criança está perto de morrer (...) a primeira pessoa que identifica pode ser eu, como enfermeira (...) a gente tem que falar logo com a família (...) ela que tem que saber se ela quer que aconteça (a morte) em casa ou não (...) saber se ela está preparada ou não (...) se têm outras crianças em casa (...) isso quem decide é a família; a gente entra em luto também; eu entrei em luto por causa de uma criança (...) (E3.1).

O entendimento da situação de doença da criança perpassa pela visão espiritual da família e essa condição deve ser valorizada pela enfermeira para que o cuidado seja favorecido.

(...) o enfermeiro precisa trabalhar com a família (...). Que família é essa? Qual é a cultura dessa família? Qual é a religião dessa família? Qual é o entendimento que essa família tem sobre o que está acontecendo agora com seu filho? (...) (E5.2).

\section{Discussão}

Este estudo apresentou o contato cotidiano da enfermeira na oncologia pediátrica nas dimensões ação e afeto. Cenário este, permeado pela incerteza e caracterizado pelo impactante movimento de cuidado a crianças com câncer e suas famílias.

De acordo com o conceito de contato cotidiano (Heller, 1970), os depoimentos das enfermeiras do estudo foram analisados e articulados as dimensões que se mostraram mais expressivas no estudo, a saber: ação e afeto.

Para as enfermeiras, a oncologia pediátrica foi referida como a que enseja à criança a interrupção de um ciclo de crescimento naturalmente esperado pelas pessoas. Assim, torna-se um desafio cuidar da criança portadora de câncer, principalmente quando a vida não é garantida.

Por esta razão, é preciso afastar a ideia do sucesso terapêutico atrelado à cura, uma vez que as ações de enfermagem não dependem do resultado do embate entre doença e tratamento, mas da plenitude e da intensidade do cuidado. As ações de enfermagem a criança no processo de morte necessitam ser melhoradas no ensino curricular da graduação, uma vez que a formação permanece voltada à reparação da saúde, e durante a atuação profissional das enfermeiras os espaços de reflexão, de diálogo e de troca de experiências sobre a terminalidade infantil são escassos (Andrade, da Cunha \& Biondo, 2020).

Neste contexto, constatou-se o movimento de desafios e de estratégias ora técnicas ora simbólicas carregadas de afetos e (des) afetos no espaço das relações entre as enfermeiras, crianças e sua família. 
As ações apontadas pelas enfermeiras mostraram o desafio em se executar procedimentos técnicos, especialmente os invasivos, específicos da especialidade considerando que a criança carrega todo um contexto de expectativa de vida, de futuro, de não merecimento da tristeza, da dor e do sofrimento. Os profissionais que atuam na oncologia pediátrica enfrentam um grande desafio, saber lidar com as próprias emoções que são experimentadas durante esse convívio (Aires \& Bandeira, 2021). Assim, as enfermeiras ao cuidarem de crianças com câncer vivenciam uma constante transformação $e$ movimento em seu cotidiano, resultando em uma práxis que vai além do espaço físico e das habilidades técnicas (Siman, de Matos, \& de Mendonça, 2019).

A doença e o tratamento estampados na face e no corpo da criança suscitam sentimentos de empatia e compaixão das enfermeiras. Neste sentido, as enfermeiras, por lidarem com a morte, especialmente de crianças oncológicas, costumam sofrer impactos devastadores em sua capacidade relacional, racional e emocional. Na tentativa de entender a dor e o sofrimento do outro, essas profissionais podem vivenciar sentimentos negativos e prejudiciais à sua saúde por absorver demasiadamente os problemas do paciente e de sua família (Reis \& Souza, 2019).

Por outro lado, as enfermeiras citaram como foi possível adequar as atitudes e os ambientes para facilitar as práticas assistenciais. Diante da ausência de uma abordagem institucional com foco na criança, é possível recriar ações e procedimentos. Usar tecnologias lúdicas modelando o ambiente e o contexto do cuidar com atitudes que estimulem a criança a interagir de maneira positiva. Para isso, é indispensável que a enfermeira se disponha a adquirir novas habilidades, a trabalhar em equipe, a desenvolver mecanismos que transcendam o modelo fragmentado.

A assistência em enfermagem oncológica requer do profissional de saúde, seja qual for à situação de doença na criança ou suas implicações no cotidiano de sua família, um olhar amplo e humanizado, que precisa estar atento as práticas e cuidados na oncologia pediátrica (Aires \& Bandeira, 2021. A cultura religiosa e as crenças podem ajudar e é preciso compreender como as pessoas encaram o processo da doença e de que forma seus contextos de vida influenciam neste enfrentamento (de Moura Souza, Frizzo, de Paiva, Bousso, \& da Silva Santos, 2015).

Nos aspectos familiares, as depoentes destacaram que é preciso reconhecer nos pais um binômio (criança-família) que favoreça a prática de um modelo assistencial inclusivo, mais próximo à necessidade singular de cada criança. Entretanto, elas admitem que os desafios que se tem nos espaços de internação pediátrica atualmente se mostrem distantes de um fluxo de cuidado sistematizado, particularizado e com o foco na família. Neste sentido, discutir a ação das enfermeiras, linhas de frente desse cuidado, abre a possibilidade de oportunizar caminhos para a qualificação da assistência à criança e sua família no cenário hospitalar.

No tocante as condições de trabalho, vários depoimentos destacaram que o dimensionamento de pessoal é desproporcional as necessidades da especialidade, resultando em uma categoria de profissionais fadigados. Existe um quantitativo muito grande de procedimentos a serem realizados e a jornada de trabalho é extenuante, considerando que as ações realizadas perpassam complexos procedimentos. Estudo realizado no Instituto do Câncer em Harvard (Rodriguez-Galindo, Friedrich, Morrissey, \& Frazier, 2015) relaciona carga de trabalho da enfermeira oncologista como fator crítico na evolução dos pacientes e conclui que o número inadequado de enfermeiras resulta em maior tempo de internação, aumento do risco de complicações e um aumento na mortalidade.

O desejo do profissional em atividade laboral cotidiana é que ela facilite e com o mínimo esforço possível (necessidades normais do indivíduo) resulte na integração social isenta de conflitos (Heller, 2014).

Em face deste entendimento, a ação tem no outro o seu objetivo (Heller, 1970). Este estudo demonstrou que as ações das enfermeiras têm o desafiante movimento entre o técnico e o simbólico, conjugando a peculiaridade da criança às interfaces da doença oncológica. Para lidar com as cenas produzidas e reproduzidas no cotidiano e se sentir apto e agente do cuidar demanda grande capacidade de superação e compaixão. 


\section{Conclusão}

A partir dos depoimentos deste estudo foi possível constatar que, na dimensão ação, os aspectos relacionados ao assistir/gerenciar configuraram o cotidiano das enfermeiras. Essas ações foram permeadas por atitudes que articulam o conhecimento técnico e o simbólico. Essas ações se interpenetraram.

Os depoimentos captaram as vozes, nem sempre ouvidas, de quem assiste desde o primeiro instante da hospitalização. Assim, a enfermeira pediatra constrói e reconstrói seu espaço de ação e de afeto no cotidiano de assistir e de gerenciar em oncologia.

A enfermeira se move mediada pelos afetos do contato cotidiano, e se inclina para se estabelecer no espaço dessas relações. As depoentes demonstraram como esses sentimentos estão presentes através de suas relações com as crianças e suas famílias. O vínculo que se estabelece em razão da intensidade desse contato permeou as ações e explicaram a função essencial dos contatos cotidianos. Assim, através dos desafios e das estratégias, redesenharam a prática, reposicionaram a ação e o afeto no contato cotidiano.

Por outro lado, algumas enfermeiras que permaneceram em seu cotidiano no espaço do adoecimento, ainda que não estivessem fisicamente no cenário hospitalar, viveram continuadamente esse (des)afeto como se fosse parte de sua vida diária. Desta forma, elas prosseguem sua atividade assistencial na oncologia pediátrica com limitações pessoais e profissionais.

Contudo, encontrar estratégias para cuidar de quem cuida perpassa por admitir que o problema seja uma realidade concreta. Observou-se que as enfermeiras que lidam com crianças em fim de vida se referiram a esse trabalho com um desafio e relataram que esta situação traz impactos em suas atividades dentro dos cenários assistenciais. Não se trata apenas de capacitar para o trabalho técnico da especialidade. É imperativo que se abram espaços para discutir as emoções, as perdas, as dores.

Portanto, foi possível indicar que a enfermeira na oncologia pediátrica pertence a um espaço de encontros intensos, quer sejam longos ou breves, de perdas e superação. Sendo assim, os afetos que orientam o contato cotidiano entre as enfermeiras, as crianças e suas famílias se constituem em potencialidade da prática do cuidar para a enfermeira da oncologia pediátrica.

Diante desses resultados, concluiu-se que na dimensão afeto a compaixão move a enfermeira dando sentido ao assistir. Com isso, constatou-se que, existe um caminho para transportar ou sustentar os (des) afetos (sofrimento, medo, dor, terminalidade) oriundos do espaço de relação, ainda que possam ser limitados quando extrapolados por intensa compaixão.

Este estudo teve como limitação somente a análise das dimensões ação e afeto, portanto, recomenda-se que este referencial teórico seja utilizado em novos estudos ampliando assim, o conhecimento sobre outras dimensões do cotidiano das enfermeiras na oncologia pediátrica.

Espera-se que reflexões provocadas por este estudo tragam contribuições para o a prática assistencial de enfermagem dada a sua importância para o cuidado à saúde da criança.

\section{Referências}

Aires, J. P., \& Bandeira, A. G. (2021). The performance of nursing professionals in the health- disease process of children with oncological diseases: when death is present. Research, Society and Development, 10(1), e58110111850. https://doi.org/10.33448/rsd-v10i1.11850

Andrade, B. R. V., da Cunha, J. X. P., \& Biondo, C. S. (2020). A resiliência do enfermeiro no cuidado à criança que vivencia a terminalidade. Revista de Enfermagem da UFSM, 10, 88 .

Anjos, C. D., Santo, F. H. D. E., \& Carvalho, E. M. M. S. D. (2015). O câncer infantil no âmbito familiar: revisão integrativa. Revista mineira de enfermagem, 19(1), 227-240.

BRASIL. (2012). Conselho Nacional de Saúde. Resolução ${ }^{\circ}$ 466, de 12 de dezembro de 2012. Aprova normas regulamentadoras de pesquisas envolvendo seres humanos.

Cabral, I. E. (1998). O método criativo e sensível: alternativa de pesquisa na enfermagem. Gauthier JHM, Cabral IE, Santos I, Tavares CMM. Pesquisa em enfermagem: novas metodologias aplicadas. Rio de Janeiro: Guanabara Koogan, 302, 177-203. 
Research, Society and Development, v. 10, n. 2, e18910212249, 2021

(CC BY 4.0) | ISSN 2525-3409 | DOI: http://dx.doi.org/10.33448/rsd-v10i2.12249

de Moura Souza, V., Frizzo, H. C. F., de Paiva, M. H. P., Bousso, R. S., \& da Silva Santos, Á. (2015). Spirituality, religion and personal beliefs of adolescents with cancer. Revista Brasileira de Enfermagem, 68(5), 509-514.

de Souza Minayo, M. C., Deslandes, S. F., \& Gomes, R. (2011). Pesquisa social: teoria, método e criatividade. Editora Vozes Limitada

Heller, A. (2014). O cotidiano e a história. Editora Paz e Terra.

Heller, A. (1970). Sociología de la vida cotidiana. Península

Nunes, T. S., Canabarro, S. T., \& Carvalho, G. P. de. (2018). Construction of professional identity: motivation through experience as an oncological patient. Research, Society and Development, 7(7), e1277348. https://doi.org/10.17648/rsd-v7i7.348

Pacheco, P.Q.C. (2015) Oncologia Pediátrica: Ação e Afeto no Contato Cotidiano das Enfermeiras. Dissertação de Mestrado. Universidade Federal do Estado do Rio de Janeiro, Rio de Janeiro, RJ, Brasil.

Polit, D. F., \& Beck, C. T. (2011). Fundamentos de pesquisa em enfermagem: avaliação de evidências para a prática da enfermagem. Artmed Editora.

Rodriguez-Galindo, C., Friedrich, P., Morrissey, L., \& Frazier, L. (2015). Global challenges in pediatric oncology. Russian Journal of Pediatric Hematology and Oncology, (1), 9-24.

Siman, A. G., de Matos, R. A., \& de Mendonça, É. T. (2019). Cuidar em oncologia: desafios e superações cotidianas vivenciados por enfermeiros. Revista Brasileira de Cancerologia, 65(3). https://doi.org/10.32635/2176-9745.RBC.2019v65n3.818.

Souza, F. F., \& Reis, F. P. (2019). O enfermeiro em face ao processo de morte do paciente pediátrico. J. Health Biol. Sci.(Online), 277-283. DOI: http://dx.doi.org/10.12662/2317-3076jhbs.v7i3.2235.p277-283.2019

Vinuto, J. (2014). A amostragem em bola de neve na pesquisa qualitativa: um debate em aberto. Temáticas, 22(44). 